\title{
Idade das mães e estilo educacional na interacção com os filhos[as] que sofrem de perturbação neurótica
}

\author{
Mother's fige and Educational Style in the Interaction with Children \\ that Suffer Meurotic Disturbance \\ Edad de las madres y estilo educacional en la interacción con los hijos[as] \\ que padecen perturbación neurótica
}

\author{
Fernando Oliveira Pereira* \\ Escola Superior de Educação Almeida Garrett/Universidade Lusófona de Lisboa, Portugal.
}

Doi: dx.doi.org/10.12804/ap134.1.2016.11

\section{Resumo}

No plano psicológico há fases etárias das mães, no período de fertilidade biológica, que favorecem mais o desempenho estável e equilibrado das funções inerentes à maternidade - a educação dos filhos. Hipóteses do estudo: idades mais avançadas das mães podem ser psicologicamente menos favoráveis ao processo educacional dos seus filhos. Participantes: 189 mães distribuídas por quatro períodos etários: 20-29; 30-35; 36-40; mais de 40 anos. Instrumento metodológico: Parent Attitude Research Instrument (PARI). Os resultados do estudo revelaram que as mães à medida que avançam nos períodos etários adoptam estilos educacionais de maior hiper-protecção dos filhos(as) e estilos atitudinais de maior exigência face às tarefas desempenhadas pelos membros da família. Conclusão: conforme a idade das mães avança por escalões etários acima dos 35 anos, sendo os filhos ainda crianças, o estilo educacional apresenta maior concentração emocional nos filhos — superprotecção- e atitudes de auto-sacrifício; fac- tores que influenciam o surgimento de perturbações neuróticas na infância e adolescência.

Palavras chave: idade das mães; estilo educacional; perturbação neurótica.

\section{fbstract}

There are stages in a mother's age, during the fertility period, that are favourable to a stable and balanced motherhood in the psychological level - the children's education. Study hypothesis - Older mothers can be psychologically less capable of educating their children. Participants: 189 mothers distributed for four age periods: 20-29; 30-35; 36-40; over 40 years old. Methodological instrument: Parent Attitude Research Instrument (PARI). The study revealed that as mothers get older they adopt overprotective educational styles on their children and more demanding attitudes towards the tasks performed by other family members. Conclusion: as mothers get older (over 35 years old) and while the children are young, the educational style is guided by

* Doutorado em Psicologia; professor coordenador na Escola Superior de Educação Almeida Garrett.

A correspondência relacionada com este artigo é dirigida a Fernando Oliveira Pereira. Correio electrônico: fopereira@sapo.pt

Como citar este artigo: Pereira, F. O. (2016). Idade das mães e estilo educacional na interacção com os filhos(as) que sofrem de perturbação neurótica. Actualidades en Psicología Latinoamericana, 34(1), 157-174. doi: dx.doi.org/10.12804/apl34.1.2016.11 
their emotions - overprotection - and self sacrificed attitudes. This educational style can result in neurotic disorders during the children's childhood and adolescence. Keywords: mother's age; educational style; neurotic disorder.

\section{Resumen}

En el plano psicológico hay fases etarias de las madres, en el periodo de fertilidad biológica, que favorecen más el desempeño estable y equilibrado de las funciones inherentes a la maternidad, la educación de los hijos. Hipótesis del estudio: edades más avanzadas de las madres pueden ser psicológicamente menos favorables para el proceso educacional de sus hijos. Participantes: 189 madres distribuidas en cuatro periodos etarios: 2029; 30-35; 36-40; más de 40 años. Instrumento metodológico: Parent Attitude Research Instrument (PARI). Los resultados del estudio revelaron que las madres a medida que avanzan en los periodos etarios, adoptan estilos educacionales de mayor hiperprotección de los hijos(as) y estilos actitudinales de mayor exigencia frente a las tareas desempeñadas por los miembros de la familia. Conclusión: a medida que la edad de las madres avanza por escalones etarios por encima de los 35 años, siendo sus hijos aún niños, el estilo educacional presenta mayor concentración emocional en los hijos - sobreprotección - y actitudes de autosacrificio; factores que influencian el surgimiento de perturbaciones neuróticas en la infancia y adolescencia.

Palabras clave: edad de las madres; estilo educacional; perturbación neurótica.

A vida do ser humano subdivide-se em ciclos que correspondem a períodos etários; de entre os quais existem uns mais propícios e favoráveis à maternidade. Esta não poderá ser abordada apenas no plano da fertilidade biológica, mas também é importante ser vista no plano da maturidade psicológica para desempenhar o papel de mãe. No entanto, aqui, adquire pertinência o estudo do período etário em que as mulheres se encontram na sua plenitude psicológica e sociocultural para desempenharem as funções de mães da forma mais adequada; em particular, as educacionais no processo de interacção mães-filhos(as).

$\mathrm{Na}$ educação orientada para a formação da personalidade dos filhos papel crucial assumem as relações parentais, mas também as influências da família como grupo social onde se enfatiza a teia psicológica da dinâmica relacional que envolve as crianças em desenvolvimento. Sendo a personalidade entendida como um novelo de relações intrapessoais, a sua configuração emerge da especificidade das relações interpessoais vigentes na família e outros grupos onde a criança está inserida.

Consequentemente, os desvios existentes quer na personalidade das mães, quer nas relações que estas estabelecem com os seus filhos(as) reflectem-se nas formas e estilos educacionais, podendo assim conduzir à formação, desenvolvimento e consolidação de perturbações de comportamento e de carácter neurótico.

Assim, neste estudo, procura-se investigar qual a influência da idade das mães no estilo educacional por elas adoptado na interacção com os filhos(as) que padecem de perturbação neurótica.

\section{Enquadramento teórico}

\section{Ciclos de vida, períodos etários e maternidade}

O ciclo de vida de um ser humano, ou não, tem início no momento da sua concepção e finaliza com a sua morte. Este é o ciclo global, ou abrangente, que em conformidade com critérios definidos é divisível em vários ciclos, subciclos, ou períodos. Do ponto de vista biológico e quanto ao critério da reprodução poder-se-á distinguir três ciclos: amadurecimento ou de maturação biológica, fertilidade ou de maturidade reprodutiva e de envelhecimento reprodutivo.

Do ponto de vista fisiológico o ciclo de vida reprodutivo é assinalado por dois marcos objectivos e delimitadores do período de tempo em que ocorre. 
O primeiro marco corresponde ao aparecimento da menstruação, tecnicamente designada de menarca, e o final do ciclo biológico de fertilidade assinalado pelo segundo marco: a menopausa.

Portanto, o ciclo, ou período, de fertilidade ou maturidade reprodutiva, no plano da causalidade, é determinado por fenómenos de natureza biológica e fisiológica, impondo delimitações à possibilidade da mulher ser mãe. É o período que define biologicamente estar o ser apto para a reprodução fisiológica, mas tal como os factos da vida têm vindo a demonstrar, não significa ter esse ser humano alcançado a maturidade suficiente para ser pai ou mãe.

Assim, a maternidade, nos tempos que correm, não poderá ser vista apenas como um acto biológico ou fisiológico, mas acima de tudo importam os aspectos psicológicos e sociais. A maternidade, vista no plano das competências para cuidar e da responsabilidade pela criança, é um fenómeno mais do âmbito psicológico, psicossocial, sociocultural.

A maternidade, vista através do papel de mãe desempenhado nas diversas civilizações, é uma actividade multidimensional no seu exercício (Kitzinger, 1978). A forma como a mulher vivencia a maternidade poderá estar associada quer às suas características individuais, quer à atmosfera cultural que a circunda. Serve-lhe de pano de fundo do cenário a dinâmica da sociedade, num momento concreto historicamente determinado. Nela inscrevem-se os padrões culturais em que assumem relevância as concepções sobre a infância, a qualidade de vida, os direitos dos cidadãos (Correia, 1998; Leal, 1990).

Daqui advém que a maternidade não é um acontecimento biológico, mas corresponde a vivências inscritas na dinâmica histórico-sócio-cultural; sendo que envolve aspectos como a prestação de cuidados, as vinculações afectivas e outros ainda da mesma natureza.

Exemplificativo disto são os problemas decorrentes da maternidade em jovens ainda adolescentes, os quais fisiologicamente apresentam ma- turação para serem progenitores, mas psicológica e socialmente ainda não estão preparados; ou seja, não atingiram maturidade psicológica suficiente para serem pais e mães. É o que reflectem as descrições e interpretações encontradas nos trabalhos de vários autores, os quais investigaram sobre a temática relacionada com a maternidade e a construção da parentalidade em mães adolescentes (Almeida, 2003; Canavarro \& Pereira, 2001; Carlos et al., 2007; Figueiredo, 2000; Silva, 2012).

Para algumas mulheres ainda adolescentes a confirmação da sua feminilidade vem facilitar e precipitar a gravidez. Mas uma gravidez à qual não corresponde depois nenhum projecto de vida, nenhum projecto de ser mãe (Leal, 1992).

Então verifica-se que o período de tempo no qual se considera adequada a maturidade psicológica para ser pai ou mãe, embora coincida no tempo com uma parte do ciclo fisiológico reprodutivo, não abrange a totalidade temporal dele.

$\mathrm{Na}$ actualidade, com as mudanças operadas no entendimento da mulher e da sua feminilidade, a maternidade é concebida num contexto de projecto em conjunto com outros projectos de natureza económica e profissional, situações vivenciais que envolvem certa complexidade por razões diversas: afectivas, sócio-económicas, ou mesmo temporais. É o caso daquelas mulheres cuja pretensão passa por virem a ser mães, mas tardiamente. Condições que vêm aumentar a quantidade de mulheres, as quais fazem opções de ter o seu primeiro filho dos 35 anos em diante. É aquilo que se designa de primiparidade tardia; sendo esta cada vez mais função e consequência da diferenciação sócio-económica, tendo progressivamente maior difusão (Correia, 1998; Leal, 1990). A Organização Mundial de Saúde considera gravidez tardia a que tem lugar na mulher com mais de 35 anos, reportando-se, simultaneamente, ao grupo de gravidez de risco. No entanto, a primeira gravidez depois dos 30 anos é cada vez mais frequente; seja por falta de oportunidades, de independência dos pais, por não encontrar o par ideal, ou por privilegiar a carreira e 
a formação, facto é que pelos mais variados motivos a mulher tem o seu primeiro filho a partir dos 30-35 anos (Ballone, 2011). Em conformidade com os dados da Direcção-Geral da Saúde a quantidade de mulheres com 40 ou mais anos que foram mães cresceu em 80\% na última década (Páscoa, 2013).

Se bem que a maior parte dos factores de risco apontados na gravidez tardia são de natureza orgânica, também poderão haver alguns de natureza psicológica. O próprio medo que a designação "gravidez de risco" desencadeia pode contribuir para uma gestação emocionalmente mais difícil na sua vivência. Sendo as expectativas de risco com maior frequência atribuíveis a mulheres acima dos 35 anos (Grill, Donelli, Piccinini \& Lopes, 2008). Entretanto, é conveniente dividir os factores emocionais de risco em dois tipos: os vividos nos anos que antecederam a gravidez e aqueles que surgiram com ela (Isfer, 1997). Também se deve acrescentar que do ponto de vista psicológico as repercussões positivas ou negativas dependem em grande medida da representação que a mulher tem da gravidez e do significado que lhe atribui. Contudo, em conformidade com o perfil afectivo da gestante com mais de 35 anos poder-se-á assistir a uma postura emocional desfavorável, ou não, a qual se manifesta de entre outras formas através da ansiedade experimentada aquando da prestação de cuidados à criança no pós-parto (Reece, 1993).

H. H. Francis (1985) considera o período ideal para decorrer a gravidez entre os 20 e os 30 anos; sendo tolerável entre os 30 e os 34 anos, indesejável entre os 35 e os 39 anos e devendo ser evitada depois dos 40 anos. Não obstante o período ideal apontado para a gravidez decorrer, estudos mais recentes revelam que a idade das mães primíparas tem vindo a sofrer alterações que não seguem a orientação desejada; havendo tendência para a diminuição da participação de mulheres com menos de 24 anos e aumento de nascimentos em mães com mais de 30 anos (Carneiro, Santos \& Iozzi, 2011). Apesar desta classificação a psiquia- tria não reconhece haver maior probabilidade de problemas emocionais em gestantes com mais de 35 anos. Há que ter em conta os antecedentes de vivências psicológicas problemáticos em cada caso concreto. Contudo, dever-se-á alertar para o facto da classificação "gravidez de alto risco" precipitar mais ainda os níveis de ansiedade das mães com mais de 35 anos (Ballone, 2011). Também se têm encontrado afirmações em que a atitude materna depois dos 40 anos é diferente; que as crianças são "mal-educadas", devido aos mimos que lhe são concedidos; que estas mães habitualmente são permissivas e confundem muitas vezes o papel de mãe e de avó. F. Oliveira Pereira (2014) corrobora, descrevendo que as mães com a idade, em especial a partir dos 30 anos, têm tendência a serem mais hiper-protectoras dos seus filhos do que as mães de períodos etários inferiores.

Perante tais evidências, também se torna pertinente colocar a questão se todo o período temporal em que há maturidade psicológica, e ainda se encontra fisiologicamente fértil, para ser pai ou mãe, é adequado, ou até mesmo optimal, para dirigir e orientar o processo educacional de formação da personalidade dos filhos(as).

A exigência de uma integração psicológica interna e harmoniosa de aspectos como a satisfação profissional, a satisfação amorosa e a satisfação maternal, nem sempre é fácil de alcançar. Tanto que a mulher dos tempos modernos vive, em certa medida, em conflito consigo própria (Correia, 1998). Daí que o sentimento de maternidade só se tornará verdadeiramente vivificante para a criança quando coexiste na mãe sentimentos de conjugalidade e também interesses sociais e culturais identificativos de uma mulher com maturidade psicológica de adulto (Dolto, 1981).

\section{Família, interacção mães-filhos(as) e estilo educacional}

A personalidade não nasce com o indivíduo, no estrito acto fisiológico da maternidade. É pre- 
cisamente através dos processos de educação e de interacção social que ela se forma e desenvolve, no seio dos grupos sociais em que se encontra inserida. O grupo social com maior peso específico no processo formativo da personalidade, na infância, é a família; em suma as relações interpessoais características da funcionalidade do grupo.

A família é um grupo social de convivência intergeracional, uma unidade de pessoas em interacção, onde coexistem relações de parentesco e experiências de intimidade que se prolongam no tempo (Burgess \& Huston, 1979; Gimeno, 2003; Maxler \& Misher, 1978, citados em Gottman, 1982). E consequentemente são determinantes na configuração da estrutura da personalidade daqueles que nela estão em desenvolvimento.

Há famílias e pais em que as características de interacção fomentam a aproximação: afectuosidade, apego, vínculos afectivos, intimidade, fusão, mutualidade (Ainsworth, 1964, 1982; Bowlby, 1969, 1995; Mahoney, 1991; Soares, 1996) e outras que imprimem distanciamento: emoções negativas, rejeição, relações conflituosas, vinculação dupla (Bowlby, 1973; Gimeno, 2003). Diferenças que vêm de certa forma evidenciar que a vida espiritual e a organização da família são o reflexo da cultura histórica (Gesell \& Ilg, 1960). Mas também da personalidade do sujeito, das teias de relações em que se desenvolveu e dos significados atribuídos por ela aos acontecimentos, surgidos no decurso da sua construção.

A família é a instituição social, na qual o indivíduo adquire a sua primeira experiência socializante; os seus primeiros hábitos de comportamento social (Freud, 1933; Jung, 1964; Ribalko, 1974; Selivanov, 1975; Lacan, 1981; Relvas, 1996; Alarcão, 2000).

A família, em geral, e os pais e suas relações com os filhos, em particular, são determinantes na configuração do comportamento do indivíduo, colocando as primeiras pedras e construindo os alicerces das suas vivências iniciais, no plano emocional e da estrutura da afectividade vinculativa, do próprio comportamento, que se conserva no decorrer da vida.

No Ser humano, a formação de diferentes orientações sociais, atitudes, cultura emocional, actos comportamentais, até a sua saúde moral, espiritual e psicológica, se encontra em dependência directa do carácter da interacção intrafamiliar e da atmosfera psicológica existente na família (Andreenkova, 1971; Alarcão, 2000; Baeriunas, 1968; Sampaio \& Gameiro, 1985; Selivanov, 1975; Ushatikov, 1970; Zakharov, 1974). E consequentemente da interacção pais-filhos.

A família atenua a pressão exercida pelo mundo exterior sobre a criança e também aumenta as possibilidades desta se familiarizar com ele (Osterrieth, 1970). A família normal e adaptada no seu funcionamento social, à medida que o indivíduo se torna adulto, deixa de exercer influência socializadora e educacional primária, passando a ser secundária, em relação a instituições sociais, tais como a escola, grupos de amigos, e as vias profissionalizantes, ou seja, os espaços vivenciais que lhe correspondem.

$\mathrm{Na}$ família, como unidade sistémica, distinguem-se vários sub-sistemas, podendo cada um deles apresentar-se como a dimensão à qual se orienta o estudo: individual; conjugal; parental; fraternal (Alarcão, 2000). Este incidirá essencialmente na dimensão parental, mais concretamente na relação mãe-criança. Contudo, o desenvolvimento da funcionalidade da família, como núcleo complexo de uma rede de interacções e relações, também pode constituir-se com desvios. Por isso, especialistas da terapia familiar fizeram referência que, através de intervenções terapêuticas, é possível proceder à amplificação das flutuações do sistema familiar, conduzindo à modificação das interacções familiares, no sentido da adequabilidade funcional (Alarcão, 2000; Andolfi, 1981; Bénoit, 1997). E em consequência disso também das relações parentais, sendo estas muitas vezes influenciadas por aquelas.

Daí o sistema de relações sociais que determina e influencia os sistemas de relações intergrupais e interpessoais, os quais, por seu turno, exercerão 
acções da mesma natureza essencial no sistema intrapessoal que é, também, conhecido por personalidade, ou individualidade (Ananev, 1965, 1977; Andreiva, 1980; Bodalev, 1961, 1983; Gibbs \& Forberg, 1972).

Aqui reside a confirmação da importância dos modos e formas como as acções dos grupos sociais, especialmente as do grupo familiar nuclear e alargado, são exercidas no Ser humano em formação, desenvolvimento e aperfeiçoamento.

É neste sentido, à medida dos progressos da ciência da educação, que tem vindo a perfilhar-se o entendimento de que as formas de ensino e educação não devam contrariar as leis fundamentais da pedagogia, mas, além disso, também deverão veicular a sua direcção tomando, a cada momento, em consideração as peculiaridades estruturantes da criança sujeita à acção (Pereira, 2008; Vigotsky, 2003).

Educar - significa, em determinado grau, construir o sistema de ligações sociais e de inter-relações na colectividade, as quais geram determinadas atitudes para com ela, na actividade profissional, para com a sociedade, em geral, e para consigo próprio. Originárias do próprio indivíduo, do sistema de inter-relações entre as pessoas, as atitudes internas da personalidade transformam-se em determinadas qualidades volitivas, afectivas, gostos, hábitos morais, num determinado estilo de vida interior do Ser humano; isto é, em traços de carácter. (Ananev, 1964, p. 51)

Confirmada a importância das relações interpessoais nos grupos, especialmente as relações familiares, em geral, e, as conjugais, parentais e fraternais, em particular, na formação de atitudes e consequentemente da personalidade na infância e na adolescência, períodos de maior sensibilidade e vulnerabilidade à mudança, especial atenção será dispensada à descoberta de influências e interferências inadequadas das relações mães-filhos(as) nos desvios educacionais.

\section{Educação materna e perturbações neuróticas na infância e na adolescência}

As relações e atitudes do sistema familiar - conjugais, parentais e fraternais -, o próprio clima psicológico gerado no seio da família, encontram reflexo na formação da personalidade da criança e do adolescente, e também no estado funcional dos adultos.

A condição principal da educação correcta de crianças na família não é a sua estrutura, mas o estilo das inter-relações que a caracterizam; sejam entre os pais, ou entre pais e filhos (Dobriansky \& Skulenda, 1981).

Ideia partilhada pela maioria dos investigadores da problemática das neuroses, a propósito da influência exercida pelas relações familiares inadequadas e pelos desvios na educação sobre o surgimento de perturbações, ou anomalias, na formação da personalidade na infância e na adolescência (Decobert \& Sacco, 2000; Freud, 1933, 1996; Erickson, 1950; Messichev, 1960; Obosov, 1978; Kovalhov, 1980; Rodrigo \& Palacios, 1998; Watzlavick, Beavin \& Jackson, 1993; Zakharov, 1974).

O tipo de relação severa e injusta com as crianças, no seio familiar, poderá ser a causa do aparecimento de estados psicopatológicos; a relação exageradamente indulgente - a causa da emocionalidade excessiva; as exigências desmedidas - a causa da fraqueza psiconervosa (Ajuriaguerra, 1980; Balinsky, 1859; Ushakov, 1978).

Segundo V. N. Messichev (1960), Zatshepitsky e Iakovleva (1960) a educação em condições severas, mas de exigências e proibições contraditórias, é um factor predisposicional para a neurose obsessiva e para a psicastenia; a educação do tipo de atenção exagerada e satisfação de todos os desejos da criança desenvolve, nela, traços histéricos de carácter, com manifestações de egocentrismo, hiperactividade e ausência de autocontrolo; a apresentação às crianças de exigências, demasiado intensas para a sua idade, é um factor etiológico na formação da neurastenia. De certa forma 
poder-se-á inferir que os desvios manifestados no processo educacional exercem influência negativa no desenvolvimento da personalidade das crianças. Também se poderá conceber que os desvios expressos na educação das crianças reflectem, em si, as alterações, ou anomalias, da personalidade dos educadores. Vários autores consideram que a causa das neuroses infantis é consequência da manifestação clínico-psicológica dos problemas da família ocorridos no decurso de três, ou mais, gerações (Gimeno, 2003; Harkness \& Super, 2000; Karvassarsky, 1980, 1990; Kempinsky, 1975; Klein, 1979; Zakharov, 1974, 1982, 1998). Para Zakharov (1982, 1998) as mudanças caracterológicas e neuróticas dos pais são consequência de condições desfavoráveis da formação das suas personalidades na família antecessora, no período infantil e adolescente da sua vida. E continua: o tipo neurótico de reacção da criança é condicionado pelas peculiaridades da personalidade dos pais e pelas relações perturbadas na família.

Problemática evidenciada e confirmada na tendência de vários investigadores orientarem as suas pesquisas para a descoberta e especificação das relações entre a personalidade e a psicopatologia manifestada (Beauchesne \& Gibello, 1990; Bekhterev, 1954; Haley, 1981; Lelord \& Christophe, 1998; Michel \& Purper-Ouakil, 2009). Nuns casos é a personalidade que exerce influência nas manifestações psicopatológicas do próprio sujeito: certos traços da estrutura da personalidade materna poderão ter repercussão negativa na prematuridade (Botelho \& Leal, 2001) e também são características específicas da personalidade que dão origem a processos de psicossomatização (Karvassarsky \& Prostomolotov, 1988; Lowen, 1995; Wells, 2003). Noutros casos é a personalidade dos intervenientes que, através das disfunções nos processos de interacção e nas relações interpessoais, vão afectar a formação da personalidade de outras pessoas, em particular dos filhos (Amerikaner, Monks, Wolfe \& Tomas, 1994; Buss, 1996;; Fishel, 1998; Fiese, Wilder \& Bickham, 2000; Penington, 2002; Soares, 1996;
Soares \& Dias, 2007; Sroufe, Duggal, Weinfield \& Carlson, 2000). Então, inadequações nas formas de interacção e inter-relação das pessoas umas com as outras e dos pais com os filhos poderão deixar marcas de maior ou menor nocividade, quando as alterações são transmitidas aos sujeitos da sua incidência (Bateson, 1987; Gianino, 1989; Mattelart, 1999; Rosenthal, Finkelstein \& Roberson 1959; Sears, 1961; Spionek, 1970; Tronick \&; Weiner, 1995). Os prejuízos e os graus de nocividade são mais elevados nos períodos etários correspondentes à infância e à adolescência, porque são etapas do desenvolvimento de maior vulnerabilidade devido aos fracos recursos, por um lado, de resistência psiconeurológica e, por outro, de criticabilidade, racional e consciente, às influências externas (Berkowitz, Shapiro, Zinner \& Shapio, 1974; Kennel, 1989; Sfez, 1994; Sroufe et al., 2000).

Para alguns autores os efeitos da idade e de género refletem mais sintomas nos pais do que nas crianças, mas revelam também elevado grau de internalização de sintomas no género feminino (Wadsworth, Raviv, Santiago \& Etter, 2011). Além disso, os pais que prestam apoio emocional aos filhos atenuam significativamente os efeitos negativos do conflito interparental nas crianças, reduzindo assim as auto-atribuições de culpabilização pela discórdia parental (DeBoard-Lucas, Fosco, Rayner, \& Grych, 2010). Os contextos de conflito nas relações pais-filhos na infância são precursores de maior propensão a comportamentos anti-sociais e a estados de depressividade na adolescência, da mesma forma que contextos de segurança nas relações pais-filhos na infância correlacionam com níveis baixos de propensão antissocial e depressiva (Sentse, \& Laird, 2010).

Na maioria dos casos, os pais não têm consciência da existência, em si, de certas peculiaridades de carácter e de comportamento. Quando estas peculiaridades se manifestam no comportamento das crianças os pais adoptam formas de reacção ao fenómeno inadequadas do ponto de vista afectivo. Os pais projectam psicologicamente nos filhos 
os seus problemas pessoais e depois acabam por sentir as consequências, conjuntamente com as próprias crianças.

Isto revela que os desvios na educação provavelmente têm origem na personalidade dos pais, no clima psicossocial ou nas interacções e inter-relações estabelecidas no seio do grupo familiar. Consequentemente, as anomalias da educação, na família, ocupam lugar de destaque na etiopatogénese das neuroses nos períodos etários da infância e da adolescência.

Num estudo longitudinal que visou procurar diferenças inter-individuais no desenvolvimento de trajectórias dos diversos comportamentos das crianças ficou demonstrado que os estilos parentais autoritativo, ou de autoridade, autoritário, indulgente e de não envolvimento, estariam diferenciadamente relacionados com as mudanças operadas nos pais e nos filhos. Consequentemente, a autoridade parental poderá ter repercussões no desenvolvimento de sintomas, a longo prazo, nos filhos, em conformidade com os estilos adoptados pelos pais (Luyckx et al., 2011). Outros estudos revelaram que mães de crianças padecentes do transtorno de défice de atenção e hiperactividade apresentam níveis de stresse mais elevado e têm tendência a adoptar estilo parental mais coercitivo e punitivo do que as mães de crianças que não padecem desse transtorno (Yousefia, Far \& Abdolahian, 2011) e que o stresse materno correlaciona com o subtipo de transtorno de défice de atenção com hiperactividade, sendo que os sintomas de défice de atenção resultam potenciados pelo stresse (Bargas \& Lipp, 2013).

Daqui, conclui-se da existência de múltiplos factores educacionais e contextuais que interferem na formação, desenvolvimento e consolidação de perturbações psicológicas também elas diversas nos educandos.

Assim, com fundamento na análise de publicações científicas sobre a questão, coloca-se a hipótese geral de estarem as relações pais-filhos inadequadas na origem das perturbações neuróticas na infância e na adolescência, desempenhando a idade das mães papel relevante na determinação de desvios no processo educacional.

No entanto, tendo consciência da influência exercida por factores múltiplos, incluindo os do contexto de desenvolvimento da criança, este estudo incidirá especificamente no campo dos estilos e orientações educacionais adoptados pelas mães como factor importante na formação de perturbações neuróticas na infância.

\section{Método}

\section{Objectivo}

Verificar qual a influência da variável etariedade das mães no estilo educacional implementado na interação relacional com os filhos(as) e consequentemente que influência exerce estes estilos no aparecimento de perturbações neuróticas nas crianças e adolescentes.

\section{Participantes}

A amostra é constituída por 189 mães de crianças e adolescentes padecentes de perturbação neurótica. Formando estas mães grupos etários de pertença em conformidade com a idade que têm no momento da avaliação. A distribuição por grupos encontra-se representada na tabela 1 .

Tabela 1

Distribuição das mães das crianças e adolescentes em conformidade com o período etário, no qual estão incluídas

Períodos etários (anos) $\quad 30-35 \quad 20-29 \quad 36-40$ Mais de 40

$\begin{array}{lllll}\text { Quantidade de sujeitos } & 25 & 63 & 55 & 46\end{array}$

Da distribuição baseada no critério "períodos etários estabelecidos" foram concebidos quatro grupos de mães das crianças e adolescentes que padecem de perturbações neuróticas. 
No primeiro grupo entram as mães do período etário formado pelo intervalo, cuja extensão é de 10 anos, indo dos 20 aos 29 anos. O segundo grupo de mães reporta-se a um intervalo, apenas, de 5 anos, indo dos 30 aos 35 anos. O terceiro grupo, tal como o segundo, também incidem no intervalo com cerca de 5 anos de extensão, reportando-se ao período etário dos 36 aos 40 anos. O quarto e último grupo de mães, na divisão implementada, apresenta o limite inferior do intervalo de 40 anos, mas não tem limite superior; isto porque as probabilidades de existirem crianças pequenas, e até adolescentes, nas idades acima dos 40 anos são significativamente menores em comparação com as idades dos grupos precedentes. Da observação analítica, da distribuição das mães na tabela, resulta que predominam as mães de crianças e adolescentes com perturbações, no intervalo dos 30 aos 40 anos, recaindo a quantidade mais expressiva de todos os grupos formados no intervalo específico de 5 anos que vai dos 30 aos 35 anos. Facto plenamente explicável pelas tradições ou hábitos actuais da maior parte dos casamentos, mais concretamente do nascimento dos filhos, se encontrarem no período que medeia entre as idades dos 23/24 anos e os 30 anos; intervalo culturalmente aceite e formalizado, até devido aos percursos de formação escolar e profissional dos cidadãos pertencentes ao género feminino.

\section{Hipóteses}

H0: não há diferenças significativas dos estilos educacionais entre os períodos etários nos quais as mães se encontram inseridas.

$\mathrm{H} 1$ : há diferenças significativas dos estilos educacionais implementados pelas mães entre todos os grupos etários.

$\mathrm{H} 2$ : há diferenças significativas dos estilos educacionais entre alguns grupos etários de mães, mas não existem entre outros.

H3: a idade mais avançada das mães repercute-se no incremento de expressividade excessiva dos estilos educacionais e consequentemente no surgimento de perturbações neuróticas na infância e na adolescência.

\section{Questões a investigar}

Quais os estilos educacionais que se diferenciam entre os grupos etários de mães? Será que a diferença de expressão dos estilos educacionais encontra maior incidência num determinado grupo etário de mães? Quais as razões porque há, ou não, maior expressividade de estilos educacionais nuns e não noutros grupos etários de mães? Quais as repercussões da maior expressividade dos estilos educacionais com a idade das mães na formação de perturbações neuróticas?

\section{Instrumentos}

O instrumento metodológico de recolha de dados recaiu fundamentalmente no questionário orientado para o estudo das relações e atitudes parentais face aos filhos(as): Parent Attitude Research Instrument (PARI).

Questionário construído por uma equipa de investigadores, cuja finalidade se destina a estudar as relações dos pais com os filhos e as atitudes que os mesmos pais manifestam para com o papel familiar (Cunha, Freitas \& Raimundo, 1993; Schaefer \& Bell, 1958; Kotásková, 1966).

O questionário é constituído por 115 juízos de valor, todos eles são afirmações acerca dos modos de educar e das posições que as pessoas assumem quanto ao papel familiar. Os juízos de valor foram agrupados, com base em técnicas objectivas, em 23 categorias, as quais se convertem em formas específicas de relações educacionais, ou sejam indícios ou sintomas. A cada uma destas categorias pertencem cinco juízos de valor.

Relativamente a cada juízo de valor existem quatro variantes de resposta, às quais são atribuídas as seguintes significações numéricas: 4: plenamente de acordo; 3: mais de acordo que em desacordo; 
2: mais em desacordo que de acordo; 1: completamente em desacordo. A soma das significações numéricas determina o nível de expressividade de cada categoria educacional.

Da aplicação de um sistema de análises - factorial e de conteúdo - aos resultados obtidos quanto às 23 categorias, resultaram 4 factores, que poderão aqui passar a ser designados por macro-categorias. Sendo que três factores representam aspectos integrais da relação dos pais com os filhos e o quarto a atitude integral para com o papel familiar:

Factor I. Contacto emocional correcto (categorias, ou escalas, 1, 14, 15, 21).

Factor II. Concentração emocional excessiva (categorias: 2, 4, 6, 10, 11, 12, 18, 20, 22).

Factor III. Distância Emocional Excessiva (categorias: $8,9,16$ ).

Factor IV. Atitude para com o papel familiar (categorias: 3, 5, 7, 13, 17, 19, 23).

Os três tipos de relações, ou sejam os três aspectos estruturantes da relação pais-filhos, categorialmente correspondem a três tipos, ou estilos, educacionais: democrático; autoritário e livre, ou anárquico.

Os autores partiram do princípio que este instrumento metodológico é o adequado para revelar o tipo de educação que os pais põem em prática; isto é, predomínio de um destes tipos de relação (atitude) no contacto com os filhos.

Da aplicação do instrumento metodológico poder-se-á determinar "o perfil de educação"; permitindo ordenar sequencialmente, quanto ao grau de importância, ou significação, as categorias, ou escalas, caracterizadoras da relação dos pais com as crianças e das atitudes que assumem relativamente ao desempenho do papel familiar. Consequentemente revelar-se-ão quais os tipos de relação educacional de maior expressão e relevância no educador em questão. A expressão numérica alcançada em cada uma das escalas reflectirá as zonas do espectro educacional que apresentam maior grau de inadequação, ou seja, aquelas que poderão sair fora dos limiares de normalidade, dos diversos elementos estruturantes da relação dos pais com as crianças.

Partindo da reflexão conceptual apresentada conclui-se que os estilos são formas específicas de actuação, resultantes da funcionalidade do mundo interior do sujeito como personalidade/individualidade (Pereira, 2008).

Então, com o objectivo de tornar a interpretação dos dados mais consistente quanto à teoria sistémica da estrutura funcional do Ser humano, tomando em consideração quer o mundo interior, psicológico, subjectivo, quer a interacção e comunicação do sujeito com o mundo exterior, procedeu-se à reformulação designativa das macro-categorias. A razão consistiu na tentativa de alcançar maior grau de adequabilidade à conceptualização psicológica e psico-educativa. A reformulação foi restringida apenas à semântica, não alterando nada no que respeita à estrutura essencial do instrumento.

Consequentemente, na variante reformulada das categorias do instrumento (PARI), reconhece-se a sua orientação integral para traçar o Perfil dos Estilos Educacionais, adoptado pelos pais na educação dos filhos. Da nova configuração semântica e conceptual das categorias resultou a seguinte designação:

I. Estilo educacional correcto e equilibrado.

II. Estilo educacional híper-protector: concentração emocional e racionalidade compensatória do "Eu".

III. Estilo educacional hipo-protector: distanciação emocional e racionalidade defensiva do "Eu".

IV. Estilo atitudo-funcional no grupo familiar.

\section{Resultados}

Neste estudo apenas serão expostos e interpretados os resultados referentes às macro-categorias, ou categorias, acima mencionadas, abdicando as- 
sim de resultados respeitantes às categorias, ou sub-categorias, as quais representariam orientações educativo-relacionais específicas. Por conseguinte, deliberadamente foi feita a opção de proceder à análise apenas de macro-categorias, ou categorias, que por seu turno se apresentam como a expressão integral das orientações, correspondendo, na perspectiva da conceptualização psicológica e psico-educacional, aos estilos educacionais.

Entretanto, na tabela que se segue também só foram registados os valores correspondentes à existência de diferenciações estatísticas significativas, tendo-se abdicado de todos aqueles que não obedeciam a este critério.

Na tabela 2, tal como já referido, os resultados expostos reportam-se exclusivamente aos factores integrais, correspondentes interpretativamente aos estilos educacionais, não tendo sido feita qualquer alusão de registo a componentes que integram estes factores, as quais são assumidas interpretativamente na condição de orientações educativo-relacionais. Dos registos é de salientar as diferenças ínfimas de expressividade de valores obtidos entre os grupos etários de mães: 20-29, 30-35 e 36-40 anos. No entanto, entre estes grupos de mães separadamente e o grupo com idades superiores a 40 anos são identificadas diferenças estatisticamente significativas. Contudo, ao que parece, apenas em dois estilos: o educacional hiper-protector e o atitudo-funcional.

As diferenças de médias aritméticas, entre si, encontradas nos grupos que compõem os escalões etários até aos 40 anos, à primeira vista, não parecem ser suficientes para que tivesse existido significância estatística.

No que respeita ao estilo educacional designado de hiper-protecção, ou concentração emocional excessiva, entre os grupos de mães 20-29 anos e 3035 anos as médias aritméticas dos valores obtidos são praticamente idênticas, sendo que no grupo de mães 36-40 anos se verifica um crescimento das médias, embora diminuto, comparativamente aos dois grupos anteriores. É, então, possível dizer que à medida que se avança nos escalões etários há tendência para o crescimento dos valores de expressividade do estilo abordado. As diferenças estatísticas significativas só aparecem, verdadeiramente, quando se comparam os grupos dos escalões

Tabela 2

Comparabilidade dos estilos educacionais das mães de crianças e adolescentes padecentes de neurose, quanto ao critério períodos etários: 20-29 anos; 30-35 anos; 36-40 anos e mais de 40 anos, a cujos grupos as mães pertencem

\begin{tabular}{|c|c|c|c|c|}
\hline $\begin{array}{l}\text { Grupos } \\
\text { Estilos }\end{array}$ & $\begin{array}{c}\text { Grupo de mães pertença dos } \\
\text { períodos etários distribuídos } \\
\text { entre os 20-40 anos }\end{array}$ & $\begin{array}{l}\text { Grupo de mães pertença do } \\
\text { período etário com mais de } 40 \\
\text { anos }\end{array}$ & $\begin{array}{c}\text { Critério } t \\
\text { de Student }\end{array}$ & $\begin{array}{c}\text { Nível de } \\
\text { significância } \\
\text { estatística } p<\end{array}$ \\
\hline Factor II & $\begin{array}{l}20-29 \text { anos } \\
M=13.541\end{array}$ & $\begin{array}{l}\text { Mais de } 40 \text { anos } \\
\qquad M=14.337\end{array}$ & 1.742 & .050 \\
\hline $\begin{array}{l}\text { Estilo educacio- } \\
\text { nal hiper-pro- } \\
\text { tector }\end{array}$ & $\begin{array}{l}30-35 \text { anos } \\
M=13.534 \\
36-40 \text { anos } \\
M=13.709\end{array}$ & $\begin{array}{l}\text { Mais de } 40 \text { anos } \\
\qquad M=14.337 \\
\text { Mais de } 40 \text { anos } \\
M=14.337\end{array}$ & 2.198 & .050 \\
\hline Factor IV & $\begin{array}{l}30-35 \text { anos } \\
M=13.858\end{array}$ & $\begin{array}{c}\text { Mais de } 40 \text { anos } \\
M=14.337\end{array}$ & 1.966 & .050 \\
\hline $\begin{array}{l}\text { Estilo atitudinal } \\
\text { na família }\end{array}$ & $\begin{array}{l}36-40 \text { anos } \\
M=14.019\end{array}$ & $\begin{array}{c}\text { Mais de } 40 \text { anos } \\
M=14.337\end{array}$ & 1.442 & .100 \\
\hline
\end{tabular}


etários mencionados com o grupo etário de mães acima dos 40 anos; verificando-se que houve lugar a uma subida considerável dos valores aritméticos das médias neste grupo de mães.

Assim, as mães das crianças e adolescentes, de ambos os géneros, padecentes de neurose, inseridas no escalão etário acima dos 40 anos, comparativamente às mães que constituem todos os outros escalões etários, localizados abaixo dos 40 anos, adoptam o estilo educacional de carácter hiper-protector de forma mais expressiva, tendo tendência a concentrarem-se mais emocionalmente nos seus filhos, talvez rasando os contornos da excessividade $(p<.05)$. Sendo que nestas condições poderá, eventualmente, exercer influências mais nefastas nos educandos.

No respeitante ao estilo atitudo-funcional no seio da família verificam-se as mesmas tendências de expressividade de valores das médias aritméticas já registadas no outro estilo educacional. Assiste-se ao aumento de valores de expressão entre os grupos de mães dos escalões etários 30-35 e 36-40 anos à medida que se avança na idade; contudo a diferença não parece ser estatisticamente significativa. No entanto, a diferença só se torna verdadeiramente significativa aquando da comparação destes grupos de mães, pertença de escalões etários até aos 40 anos, e o grupo de mães com mais de 40 anos de idade $(p<.05)$. Consequentemente, à medida que se avança nos escalões etários de pertença das mães de crianças e adolescentes padecentes de neurose há incremento nos valores de expressividade no estilo atitudo-funcional adoptado no seio do grupo familiar, sendo estatisticamente significativo na representação das mães pertencentes ao escalão etário acimas dos 40 anos de idade.

\section{Discussão}

Da figura 1 é visível a discrepância entre os valores de expressividade obtidos pelos grupos etários de mães até aos 40 anos e o grupo das mães cuja idade é superior a 40 anos, quer no estilo educacional caracterizado de hiper-protector, ou seja de concentração emocional excessiva das mães nos filhos, quer no estilo atitudo-funcional no seio da família, relativamente ao envolvimento dos seus membros no desempenho de tarefas.

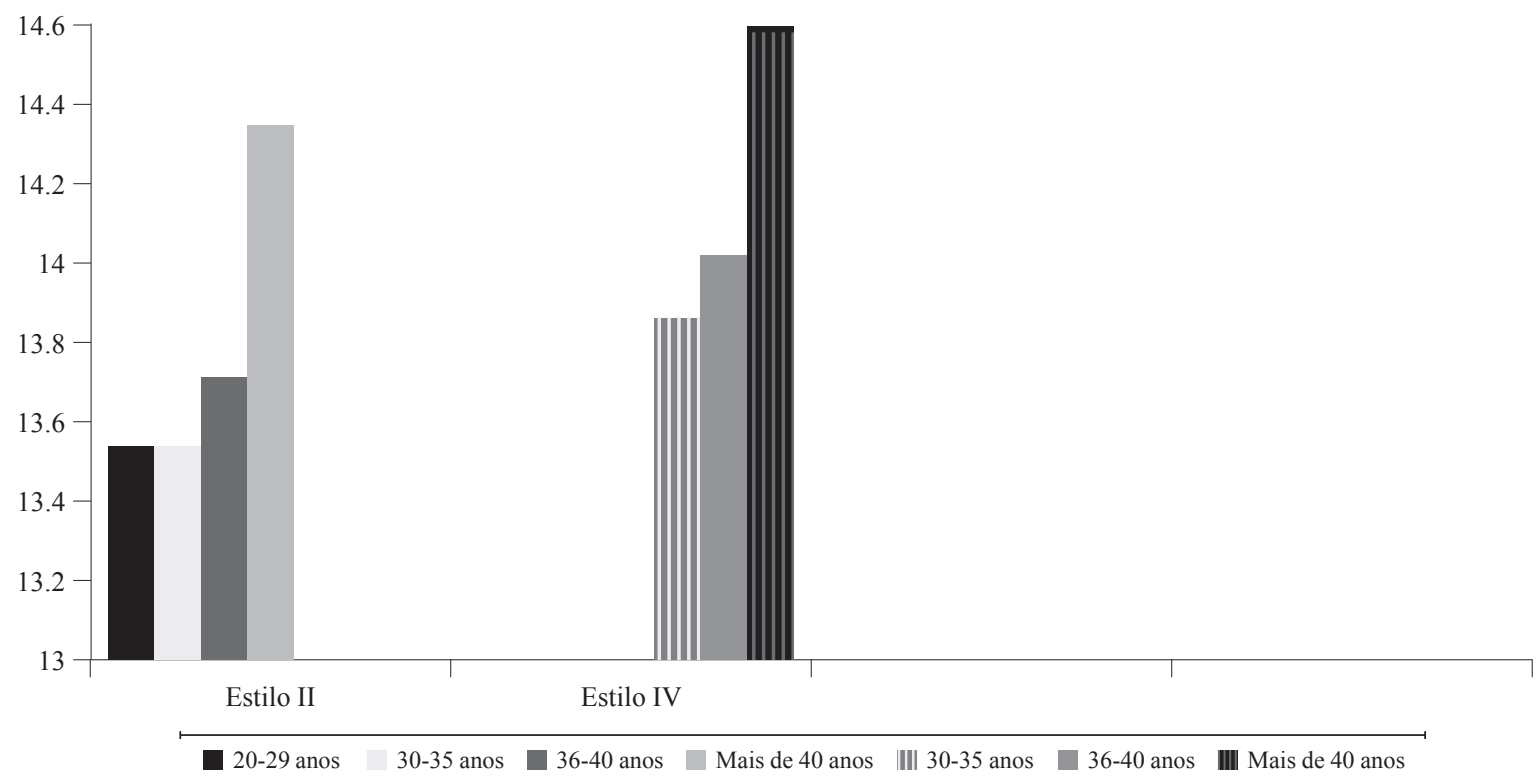

Figura 1. Expressividade dos estilos educacional de hiperprotecção (II) e atitudo-funcional no seio da família (IV) em dependência da idade das mães 
Resultados que de certa forma vêm demonstrar a contradição estratégica gerada pela tendência, nas últimas décadas, de algumas mulheres, cada vez mais, terem a pretensão de serem mães, mas só depois dos 35 anos; na maior parte dos casos devido a projectos relacionados com a sua vida profissional. Sendo que com o avançar da idade das mães pelos escalões etários referentes a este estudo denota-se maior propensão educacional para adoptar estilos de proteccionismo emocional excessivo dos filhos e de expressar com maior frequência atitudes de desagrado quanto ao seu papel, mas também dos outros membros, relativamente ao envolvimento no desempenho de tarefas inerentes à funcionalidade da família.

Provavelmente, as mães do escalão etário acima dos 40 anos revelam maior tendência de propensão psicológica a ressentirem-se e a fazerem mais juízos de valor acerca da sua sacrificação maternal em prol dos filhos e da falta de reconhecimento e de colaboração por parte dos outros membros da família nuclear.

Talvez, seguindo o raciocínio lógico das mudanças operadas nas pessoas ao longo do processo de desenvolvimento, especialmente na fase descendente, muitas vezes também chamado de processo de envelhecimento, nas mães com mais de 40 anos já se faça sentir o peso da redução, ou diminuição, dos graus de plasticidade neurofuncional e, consequentemente, de flexibilidade e agilidade psicológica, psico-educacional, de comunicação interaccional e comportamental, dificultando a adaptação e optimização dos seus recursos internos, assim como a sua disponibilidade emocional às exigências educacionais, principalmente no plano energético e de actividade dos seus filhos. Vindo deste modo a aumentar os índices de stresse e de tensão psiconervosa vividos pelas mães, crescendo progressivamente certa incapacidade para acompanhar as actividades implementadas pelos filhos; por serem demasiado exigentes e desgastantes do ponto de vista da energia, em especial para pais, em particular mães, cuja idade se enquadra na faixa etária em que na maioria das mães os filhos já são jovens adultos. Mas também para aquelas mães que no decorrer da sua vida adulta se habituaram a estarem sempre, ou quase sempre, ocupadas com outras actividades menos exigentes do ponto de vista do desgaste energético, da disponibilidade atencional e até da versatilidade mimica e emocional.

Além disso, a tendência crescente dos valores de expressão do estilo educacional com contornos de hiperprotecção e do estilo atitudo-funcional, face à percepção da participação e colaboração dos outros membros da família no desempenho de tarefas do lar, nas mães, à medida que estas progridem pela passagem de pertença a escalões etários cada vez mais avançados, provavelmente vem denunciar, ou até demonstrar, a existência de índices de maior cristalização no que respeita à funcionalidade adaptacional da sua personalidade aos novos contextos situacionais e circunstanciais. Consequentemente, as mães dos escalões etários acima dos 35 anos, em particular depois dos 40 anos, em conformidade com os graus de cristalização da personalidade apresentarão objectivamente maior rigidez e menor flexibilidade funcional e adaptacional, tornando-as mais resilientes à mudança e à aceitação de variações do comportamento dos filhos(as), ainda que estes ocorram dentro dos parâmetros de normalidade aceitáveis para a idade. Então, verificar-se-á que com regularidade passaram a dominar nestas mães atitudes de maior impaciência e de implicância no que respeita aos comportamentos manifestados pelos seus filhos(as) quando ainda crianças. Também se poderá, nas condições de existência de morbilidade, haver lugar ao agravamento dos traços de carácter, em especial das suas formas características de reacção comportamental, destas mães quando têm que mobilizar os seus recursos internos nas condições de interacção activa com os filhos(as). Ao que parece evidenciam-se aqui algumas premissas da paradoxalidade das reacções comportamentais emergentes da contradição dialéctica de certa forma disfuncional entre duas partes do sistema interactivo. Sendo que uma das partes 
- a criança -, por inerência ao seu desenvolvimento, é activa e dotada de elevada plasticidade e flexibilidade comportamental, enquanto a outra — a mãe —, por inerência à sua condição etária e funcional da personalidade, revela cada vez menor flexibilidade e menor grau de adaptabilidade comportamental, mas principalmente de aceitabilidade de certas condutas mais activas e exigentes dos filhos(as).

\section{Conclusões}

Existem diferenças de expressividade dos estilos educacionais e atitudinais preconizados pelas mães pertencentes aos vários escalões etários deste estudo. Contudo, diferenças significativas com incremento da expressividade dos estilos só existem nos grupos etários 36-40 anos e superior a 40 anos.

Nos últimos tempos, a tendência de algumas mulheres para a primiparidade depois dos 35 anos, por causa dos seus projectos profissionais, embora ganhem maior tranquilidade relativamente às condições sócio-económicas, poderão perder no que respeita às suas condições psicológicas, devido à possível redução no grau de flexibilização funcional, quando envolvidas no processo activo de interacção com os filhos. Afirmações corroboradas pelas posições assumidas por diversos autores (Grill et al., 2008; Pereira, 2014; Zakharov, 1998).

As mães com mais de 40 anos parecem revelar maior propensão psicológica a ressentirem-se da pressão psicológica resultante da permanente atenção educacional exigida e também a manifestarem mais atitudes de desagrado por terem a percepção de estarem a ser sacrificadas em prol dos filhos, agravando-se ainda pela percepção de falta de reconhecimento e de colaboração dos outros membros da família nuclear. Conclusão reportada também em estudos antes realizados no âmbito desta temática (Leal, 1992; Pereira, 2014; Zakharov, 1998).

Com base na lógica do processo de envelhecimento, provavelmente, as mães de idades acima dos
40 anos já se ressentem da diminuição do índice de plasticidade neurofuncional e, em consequência disso, também da flexibilidade e agilidade psicológica, psico-educacional e comportamental. Funcionalidades que se reflectem, dificultando, na adaptação e optimização dos seus recursos energéticos e disponibilidade mental às exigências educacionais inerentes à condição etária dos filhos. Tal como indiciam várias fontes literárias (Ballone, 2011; Pereira, 2014).

Os resultados obtidos neste estudo e consequentes conclusões poderão ter relevância, ainda que relativizada, na condição de contributo à compreensão de alterações nos estilos educacionais das mães à medida que estas avançam na idade e que as mudanças operadas poderão ter repercussões negativas no processo de desenvolvimento da personalidade dos seus filhos. Por outro lado, também poderão contribuir, no âmbito da educação para a saúde e para o exercício de cidadania mais consistente nas suas convicções relativas a projectos de vida, nas diversas instituições com intervenção responsável e directa pela optimização de recursos de apoio à maternidade, para o esclarecimento, sensibilização e consciencialização de futuras mães, quanto às questões psicológicas relacionadas com a idade.

\section{Referências}

Ainsworth, M. D. (1964). Patterns of attachment behavior seen by the infant interaction with his mother. New York: Merril-Palmer Quaterly. Ainsworth, M. D. (1982). Attachment: Retrospect and prospect. Em C. M. Parkes \& Stevenson-Hinde (Comps.), The place of attachment in human behavior. New York: Basic Books.

Ajuriaguerra, J. (1980). Manual de psiquiatria infantil. Rio de Janeiro: Masson.

Alarcão, M. (2000). (Des) equilibrios familiares. Coimbra: Quarteto.

Almeida, J. M. R. (2003). Adolescência e maternidade ( $2^{\mathrm{a}}$ ed.). Lisboa: Fundação Calouste Gulbenkian. 
Amerikaner, M., Monks, G., Wolfe, P. \& Tomas, S. (1994). Family interaccion and individual psychological health. Journal of Counseling and Development, 72(6), 614-620.

Ananev, B. G. (1964). Aplicação pedagógica da psicologia contemporânea. Pedagogia Soviética, 8, 55-64. Moscovo: Pedagogia.

Ananev, B. G. (1965). O homem como objecto da educação. Pedagogia Soviética, 1, 24-37

Ananev, B. G. (1977). Sobre os problemas do conhecimento do Ser humano actual. Moscovo: Ciência.

Andolfi, M. (1981). A terapia familiar. Lisboa: Vega. Andreenkova, N. V. (1971). O papel da família na socialização do indivíduo. Em Problemas de vida quotidiana do casamento e da família (pp. 162-172). s. 1.: Vilnius.

Andreiva, G. M. (1980). Psicologia social dos grupos e da personalidade. Em Psicologia social (pp. 175-352). Moscovo: Universidade Estatal de Moscovo.

Baeriunas, E. V. (1968). Experiência do estudo sócio-psicológico da família do adolescente delinquente. Em Questões de estudo das crianças com desvios de comportamento (pp. 20-49). Moscovo: Psicologia.

Balinsky, I. M. (1859). Curso de sessões sobre as doenças do espírito. Moscovo: SPB.

Ballone, G. J. (2011). Gravidez depois dos 35 anos. Em PsiqWeb. Recuperado em http://www.psiqweb.med.br.

Bargas, J. A. \& Lipp, M. E. N. (2013). Estresse e estilo parental materno no transtorno de deficit de atenção e hiperactividade. Revista de Psicologia Escolar e Educacional, 17(2), 205-213.

Bateson, G. (1987). Metadiálogos. Lisboa: Gradiva.

Beauchesne, H. \& Gibello, B. (1990). Traité de psychopathologie infantile. Paris: PUF.

Bekhterev, V. M. (1954). Publicações seleccionadas. Moscovo: Medgiz.

Bénoit, J. C. (1997). Tratamento das perturbações familiares. Lisboa: Climepsi.
Berkowitz, D. A., Shapiro, R. L., Zinner, J. \& Shapio, E. R. (1947). Family contributions to narcissistic disturbances in adolescents. International Journal of Psychoanalysis, 1(3), 353-362.

Bodalev, A. A. (1961). Sobre a relação e o modo de auto-expressão nos adolescentes. Em Questões da aprendizagem na educação (pp. 122-124). Kiev: Psicologia Pedagógica.

Bodalev, A. A. (1983). Personalidade e comunicação. Moscovo: Prosveshenie.

Botelho, T. M. \& Leal, I. P. (2001). Personalidade materna e prematuridade. Lisboa: SNR.

Bowlby, J. (1969). Attachment and loss: Attachment (Vol. 1). New York: Basic Books.

Bowlby, J. (1973). Attachment and loss: Separation (Vol. 2). New York: Basic Books.

Bowlby, J. (1995). Una base segura: aplicaciones clínicas de una teoria del apego ( $2^{\mathrm{a}}$ ed.). Barcelona: Paidós.

Burguess, R. L. \& Huston, T. L. (Eds.) (1979). Social exchange in developing relationships. New York: Academic Press.

Buss, D. M. (1996). Paternity Uncertainly and the complex repertoire of human mating strategies. Journal of American Psychological Association, 51(2), 950-952.

Canavarro, M. C. \& Pereira, A. I. (2001). Gravidez e maternidade na adolescência: perspectivas teóricas. Em M. C. Canavarro (Ed.), Psicologia da gravidez e da maternidade. Coimbra: Quarteto.

Carlos, A. I., Pires, A., Cabrita, T., Alves, H., Araújo, C. \& Bentes, M. H. (2007). Comportamento parental de mães adolescentes. Análise Psicológica, 25(2), 183-194.

Carneiro, A., Santos, L. \& Iozzi, R. (2011). Maternidade adiada-novos padrões reprodutivos. Rio de Janeiro: Secretaria Municipal de Saúde e Defesa Civil do Rio de Janeiro. Recuperado de: http://www.rio.rj.gov.br/web/smsdc/

Correia, M. J. (1998). Sobre a maternidade. Análise Psicológica, 3(XVI), 365-371. 
Cunha, J. A., Freitas, N. K. \& Raimundo, M. G. B. (1993). Psicodiagnóstico-R. Porto Alegre: Artes Médicas.

DeBoard-Lucas, R. L., Fosco, G. M., Rayner, S. R., \& Grych, J. H. (2010). Interparental conflict in context: Exploring relations between parenting processes and children's conflict appraisals. Journal of Clinical Child \& Adolescent Psychology, 39(2), 163-175.

Decobert, S. \& Sacco, F. (Coords.). (2000). O desenho no trabalho psicanalítico com a criança. Lisboa: Climepsi.

Dobriansky, B. V. \& Skulenda, N. M. (1981). A estrutura da família e a formação da personalidade da criança. Em Família e a personalidade. Moscovo: s.e.

Dolto, F. (1981). No jogo do desejo. Rio de Janeiro: Imago.

Erickson, E. H. (1950). Childhood and society. New York: Norton.

Fiese, B. H., Wilder, J., \& Bickham, N.L. (2000). Family context in developmental psychopathology. Em A. J. Sameroff, M. Lewis, \& S. M. Miller, Handbook of developmental psychopathology (2a ed.). New York: Springer.

Figueiredo, B. (2000). Maternidade na adolescência: consequências e trajectórias desenvolvimentais. Análise Psicológica, 18(4), 485-498.

Fishel, E. (1998). Relações entre pais e filhos. Lisboa: Presença.

Francis, H. H. (1985). Delayed childbearing. IPPF Medical Bulletim, 19(3), 3-4.

Freud, S. (1933). Nouvelles conférences sur la psychoanalyse. Paris: Gallimard.

Freud, S. (1996). Obras completas. Rio de Janeiro: Imago.

Gesell, A. \& Ilg, F. L. (1960). Le jeune enfant dans la civilization modern. Paris: Presses Universitaires de France.

Gibbs; G. \& Forberg, M. (1972). Introdução à psicologia social marxista. Moscovo: Progresso.

Gimeno, A. (2003). A família: o desafio da diversidade. Lisboa: Instituto Piaget.
Gottman, J. M. (1982). Temporal form: Toward a new language for describing relationships. Journal of Marriage and the Family, 4, 943-962.

Grill, G. A., Donelli, T. M. S., Piccinini, C. A., \& Lopes, R. C. S. (2008). Maternidade em idade avançada: aspectos teóricos e empiricos. Interacção em Psicologia, 12(1), 99-106.

Haley, J. (1981). Pour une théorie dês sistèmes pathologiques. Em P. Watzlawick \& J. H. Weakland, Sur l'Interaction. Paris: Le Seuil.

Harkness, S. \& Super, Ch. M. (2000). Culture and Psychopathology. Em A. J. Sameroff, M. Lewis, \& S. M. Miller, Handbook of developmental psychopathology (2a ed.). New York: Springer.

Isfer, E. (1997). Medicina fetal: o feto, o paciente. Em J. Wilheim (Org.), Decifrando a linguagem dos bebés: Anais do Segundo Encontro Brasileiro para o Estudo do Psiquismo Pré e Peri-Natal (pp. 181-192). São Paulo: Cop L Print.

Jung, C. G. (1964). Dialectique du Moi et de l'incoscient. Paris: Gallimard.

Karvassarsky, B. D. (1980). Neuroses. Moscovo: Meditsina.

Karvassarsky, B. D. (1990). Neuroses ( $2^{\mathrm{a}}$ ed.). Moscovo: Meditsina.

Karvassarsky, B. D. \& Prostomolotov, V. F. (1988). Perturbações neuróticas dos órgãos internos. Kishinev: Shtiintsa.

Kempinsky, A. (1975). Psicopatologia das neuroses. Varsóvia: Medicina.

Kennel, J. H. (1989). Biopsychology of early parent-infant comunication. Em International Symposium of Biopsychology of Early Parent-Infant Comunication. Lisboa: Fundação Calouste Gulbenkian.

Kitzinger, S. (1978). Mães: um estudo antropológico da maternidade. Lisboa: Presença.

Klein, M. (1979). D`oú vient la névrose. Em Les névroses: l home e ses conflits (pp. 275-309). Paris: Tchou.

Kovalhov, A. G. (1980). Psicologia da educação familiar. Minsk: Luz do Povo. 
Kotásková, J. (1966). Metody zamerené na interakci rodicù a detí. In Cs. Psychol, 1, 53-57.

Lacan, J. (1981). A família (2 ${ }^{\mathrm{a}}$ ed.). Lisboa: Assírio e Alvim.

Leal, I. (1990). Nota de abertura. Análise Psicológica, 8(4), 365-366.

Leal, I. (1992). Psicologia da maternidade: alguns aspectos da teoria e prática de intervenção. Análise Psicológica, 2(X), 229-234.

Lelord, F. \& Christophe, A. (1998). Como gerir personalidades dificeis. Lisboa: Instituto Piaget.

Lowen, A. (1995). La depresión y el cuerpo (5 $5^{\mathrm{a}} \mathrm{ed}$.). Madrid: Alianza.

Luyckx, K., Tildesley, E. A., Soenens, B., Andrews, J.A., Hampson, S. E., Peterson, M. \& Duriez, B. (2011). Parenting and trajectories of children`s maladaptative behaviors: a 12-year prospective community study. Journal of Clinical Child \& Adolescent Psychology, 40(3), 468-478.

Mahoney, M. J. (1991). Human change processes. Em The scientific foundations of psychotherapy. New York: Basic Books.

Mattelart, A. (1999). A mundialização da comunicação. Lisboa: Instituto Piaget.

Messichev, V. N. (1960). A personalidade e as neuroses. Leninegrado: Universidade Estatal de Leninegrado.

Michel, G. \& Purper-Ouakil, D. (2009). Personalidade e desenvolvimento: do normal ao patológico. Lisboa: Instituto Piaget.

Obosov, N. N. (1978). Relações interpessoais. Leninegrado: Universidade Estatal de Leninegrado.

Osterrieth, P. (1970). A criança e a família. Lisboa: Europa-América.

Páscoa, E. (2013). Mãe mais tarde: ter o primeiro filho depois dos 35 anos é cada vez mais comum. Conheça os principais riscos. Revista Pais \& Filhos (267).

Pennington, B. F. (2002). The development of psychopathology: Nature and nurture. New York: The Guilford Press.

Pereira, F. O. (2008). Especificidade psicológica da imagem representacional dos estilos persona- lístico-comportamentais dos profissionais de educação. Porto: Ecopy.

Pereira, F. O. (2014). Educação e Neuroses. Lisboa: Sinapis.

Reece, S. M. (1993). Social support and the early maternal experience of primíparas over 35 . Maternal-Child Nursing Journal, 21(3), 91-98.

Relvas, A. P. (1996). O ciclo vital da família: perspectiva sistémica. Porto: Afrontamento.

Ribalko, E. F. (1974). A formação da personalidade. Em Psicologia social da personalidade (pp. 20-32). Leninegrado: Universidade Estatal de Leninegrado.

Rodrigo, M. \& Palacios, J. (Coords.). (1998). Família $y$ desarrollo humano. Madrid: Alianza.

Rosenthal, M. J., Finkelstein, M., \& Roberson, R. E. (1959). A study of mother relationship in the emotional disorders of children. Genetic Psychology Monographs, 60, 65-116.

Sampaio, D. \& Gameiro, J. (1985). Terapia familiar. Porto: Afrontamento.

Schaefer, E. S. \& Bell, R. Q. (1958). Development of a parental attitude research instrument. Child Development, 29, 339-362.

Sears, R. R. (1961). The relation of early socialization experiences to agression in middle childhood. Journal Abnormal Social Psychology, 63, 466-492.

Selivanov, V. I. (1975). A família como colectividade. Em Colectividade e personalidade (pp. 105115). Moscovo: Ciência.

Sentse, M. \& Laird, R. D. (2010). Parent-Child relationships and dyadic friendship experiences as predictors of behavior problems in early adolescence. Journal of Clinical Child \& Adolescent Psychology, 39(6), 873-884.

Sfez, L. (1994). Crítica da comunicação. Lisboa: Instituto Piaget.

Silva, C. P. da (2012). A construção da parentalidade em mães adolescentes-um modelo de intervenção e prevenção. São Paulo: Honoris Causa.

Soares, I. (1996). Representação da vinculação na idade adulta e na adolescência, estudo 
intergeracional: mãe-filho(a). Braga: Universidade do Minho, Instituto de Educação e Psicologia.

Soares, I. \& Dias, P. (2007). Apego y psicopatología en jóvenes y adultos: contribuciones recientes de la investigación. Internacional Journal of Clinical and Health Psychology, 7, 177-195.

Spionek, H. (1970). Psychologiczna analiza trudnosci i niepowodzen szkolnych. Warszawa: PZWS.

Sroufe, L. A., Duggal, S., Weinfield, N., \& Carlson, E. (2000). Relationships, development and psychopathology. Em A. J. Sameroff, M. Lewis, \& S. M. Miller, Handbook of developmental psychopathology (2nd ed.). New York: Springer.

Tronick, E. \& Gianino, A. (1989). The transmission of maternal disturbance to the enfant. Em International Symposium of Biopsychology of Early Parent-Infant Comunication. Lisboa: Fundação Calouste Gulbenkian.

Ushakov, G. K. (1978). Perturbações psiconervosas no estado border-line. Moscovo: Meditsina.

Ushatikov, A. I. (1970). Os conflitos familiares $e$ a sua influência no desenvolvimento volitivo. Leninegrado: Univ. Estatal de Leninegrado.

Vigotsky, L. S. (2003). Psicologia pedagógica. Porto Alegre: Artmed.

Wadsworth, M. E., Raviv, T., Santiago, C. C. \& Etter, E. M. (2011). Testing the adaptation to poverty-related stress model: Predicting psychopa- thology symptoms in families facing economic hardship. Journal of Clinical Child \& Adolescent Psychology, 40(4), 646-657.

Watzlavick, P., Beavin, J., \& Jackson, D. (1993). Pragmática da comunicação humana: um estudo dos padrões, patologias e paradoxos da interacção ( $9^{\mathrm{a}}$ ed.). São Paulo: Cultrix.

Weiner, I. B. (1995). Perturbações psicológicas na adolescência. Lisboa: Fundação Calouste Gulbenkian.

Wells, A. (2003). Perturbações emocionais e metacognição. Lisboa: Climepsi.

Yousefia, S., Far, A. S., \& Abdolahian, E. (2011). Parenting stress and parenting style in mothers of ADHD with mothers of normal children. Procedia-Social and Behavioral Sciences, 30, 1666-1671.

Zakharov, A. I. (1974). A educação familiar e os seus defeitos. Em Psicologia social da personalidade. Leninegrado: Universidade Estatal de Leninegrado.

Zakharov, A. I. (1982). Psicoterapia de neuroses em crianças e adolescentes. Leninegrado: Meditsina.

Zakharov, A. I. (1998). Neuroses infantis e psicoterapia. S. Petersburgo: Meditsina.

Zatshepitsky, R. A. \& Iakovleva, E. K. (1960). O papel da educação inadequada no surgimento das neuroses. Leninegrado: Meditsina.

\section{Data de recebido: 1 de outubro de 2013 Dada de aceitação: 7 de abril de 2015}

